\title{
Effect of Hot Accumulative Roll Bonding Process on the Mechanical Properties of AA5083
}

\author{
Hassan Sheikh, Ebrahim Paimozd \\ Materials Engineering Department, Malek Ashtar University of Technology, Shahin Shahr, Iran \\ E-mail:sheikh_scientific@yahoo.com \\ Received August 10, 2011; revised September 16, 2011; accepted September 25, 2011
}

\begin{abstract}
In this work, accumulative roll bonding (ARB) process as a severe plastic deformation was applied on an AA5083 sheet up to 6 cycles at the temperature of $300^{\circ} \mathrm{C}$ and at the strain rate of $50 \mathrm{~s}^{-1}$. The results of tensile tests show that the values of the yield stress and the ultimate tensile strength don't change considerably after 4 cycles. Also, transmission electron microscopy (TEM) micrograph confirmed that the microstructure has fine (sub) grains with the size of $200 \mathrm{~nm}-400 \mathrm{~nm}$.
\end{abstract}

Keywords: Grain refinement; Aaccumulative Roll Bonding; Mechanical Characterization; Aluminum Alloys

\section{Introduction}

Reducing the grain size of polycrystalline metallic materials is an economic way to improve the mechanical properties such as strength, and toughness [1,2]. The microstructure with stable fine grains is crucial in the superplastic deformation of materials [3]. Since it is practically difficult to reduce the grain size of many metallic materials such as aluminum alloys by a conventional cold working and recrystallization process, several new methods such as severe plastic deformation (SPD) are developed to manufacture ultra-fine grain (UFG) materials [2]. SPD processing techniques produce relatively small quantities of materials, are very difficult to scale up, and are unlikely to be able to produce at low cost. The principle of a SPD process includes increasing the dislocation density and transforming low angle grain boundaries (LAGBs) into high angle grain boundaries (HAGBs) [4].The net shape of the sample during processing is approximately constant, so that there is no geometric limitation on the applied strain [5].

Among SPD processes, accumulative roll bonding (ARB) can be performed by a conventional rolling mill without any special die. Also, the productivity of this process is relatively high because this process implies the potential of industrial up-scaling to a continuous production of UFGed metallic sheets or plates [6]. An ARB process is practically limited by technological constraints such as the occurrence of edge cracking. In this process, the thickness of the sheet varies between fixed limits, and very high strains can be accumulated in the material by repeating the procedure; as a result, a significant structural refinement can be achieved [6-8]. Saito [6] used the ARB process at $200^{\circ} \mathrm{C}$ to reach a microstructure with ultra-fine grains for AA5083. Although this method arised $551 \mathrm{MPa}$ for the ultimate tensile strength, it considerably reduced the value of ductility to $6 \%$. From his TEM results, it can be found that there is a high density of dislocations in grains. Indeed, the true effect of the grain size on the mechanical properties of this UFG material was obscured by the presence of a high density of dislocations. By applying a heat treatment at the temperature of $180^{\circ} \mathrm{C}$ for a long time, the density of dislocations decreases considerably [9]. Because of high strength and low ductility of this alloy at low temperatures, applying the ARB at high strain rates and low temperatures has many difficulties such as edge cracking and the necessity of a high power rolling mill. For thin sheets with the thickness of $1 \mathrm{~mm}$, a high strain can be applied by using the hot ARB process at a high strain rate to reach a fine microstructure. This method can be helpful to scale up the materials with a desirable microstructure. Therefore, studying the effect of the hot ARB on the microstructure and mechanical properties of AA5083 is the prime objective of the present work.

\section{Material and Experimental Procedure}

The as-received material used in this study was an AA5083 sheet of the chemical composition presented in 
Table 1. Figure 1 shows the unique grain color map recorded on the RD-ND cross-section of the initial sheet with a mean grain size of $13 \mu \mathrm{m}$. It can be observed that the material exhibits an equi-axed polygonal type grain structure. To achieve a good bonding, the surfaces of the two sheets with dimensions of $100 \mathrm{~mm} \times 30 \mathrm{~mm} \times 1 \mathrm{~mm}$ were degreased (in acetone) and wire brushed (by a stainless steel brush with wires of $0.4 \mathrm{~mm}$ in diameter). Plane strain rolling was conducted along the longest dimension. After surface treatment, the two sheets were stacked to make a 2-mm thick specimen and then roll bonded by $50 \%$ reduction in thickness (this corresponds to a von Misses equivalent strain of 0.8 per pass). Afterwards, the rolled sheet was cut into two pieces along the transverse direction which produced two sheets of the length approximately corresponding to the initial length before rolling. This procedure was repeated up to $6 \mathrm{cy}-$ cles so that the total equivalent strain of $\varepsilon_{\mathrm{vM}}=4.8$ was achieved. Between the rolling passes, the sheets were preheated to the temperature of $300^{\circ} \mathrm{C}$ for $5 \mathrm{~min}$ and the rolling was performed without any lubrication. The roll diameter was $150 \mathrm{~mm}$ which produced the mean strain rate of $50 \mathrm{~s}^{-1}$ during the rolling. The most severe problem in the roll bonding step was small edge cracks. In this study, in order to avoid the propagation of small edge cracks in the subsequent cycles, the edges of the roll-bonded sheets were trimmed off.

To appear the interfaces located among the layers, the RD-ND section of the sample processed by 6 cycles was heated at the temperature of $125^{\circ} \mathrm{C}$ for $12 \mathrm{~h}$, and then it was etched in a solution of $10 \%$ phosphoric acid in ethanol. By doing so, $\mathrm{Mg}_{2} \mathrm{Al}_{3}$ precipitates locate at high energy places such as interfaces and the etchant can corrode the precipices; as a result, the interfaces can appear sharply.

Transmission electron microscopy (TEM) micrograph was also obtained from the sample processed by 6 cycles of the ARB process. For doing so, thin foil was prepared by twin-jet polishing from the mid-thickness plane of the sample.

The Vickers macrohardness test was taken on the surface using $30 \mathrm{~kg}$ load. The mechanical properties of the starting material and the ARBed samples were measured by tensile tests at room temperature and the strain rate of $0.002 \mathrm{~s}^{-1}$. The test specimens were prepared with the tensile axis parallel to the rolling direction. The dimensions of the specimens were chosen according to the ASTM-E8 standard.

Table 1. Chemical composition of the material used in this work (wt\%).

\begin{tabular}{cccccc}
\hline $\mathrm{Mg}$ & $\mathrm{Mn}$ & $\mathrm{Fe}$ & $\mathrm{Si}$ & $\mathrm{Cr}$ & $\mathrm{Cu}$ \\
\hline 4.5 & 0.71 & 0.33 & 0.19 & 0.058 & 0.037 \\
\hline
\end{tabular}

Copyright (C) 2011 SciRes.

\section{Results and Discussion}

Figure 2 shows the optical micrograph observed in the RD-ND section of the sample produced by 6 ARB cycles; the bonded interfaces must be observed across the thickness of the sample. The arrow in Figure 2 shows the center of thickness. No part of interfaces was not seen without applying the heat treatment mentioned for etching. This indicates a good bonding with no delamination between sheets at each cycle under the present ARB conditions.

A TEM micrograph related to mid-thickness plane (RDTD) of 6 ARB cycles has been represented in Figure 3. The TEM image shows a feature of (sub) grains with the

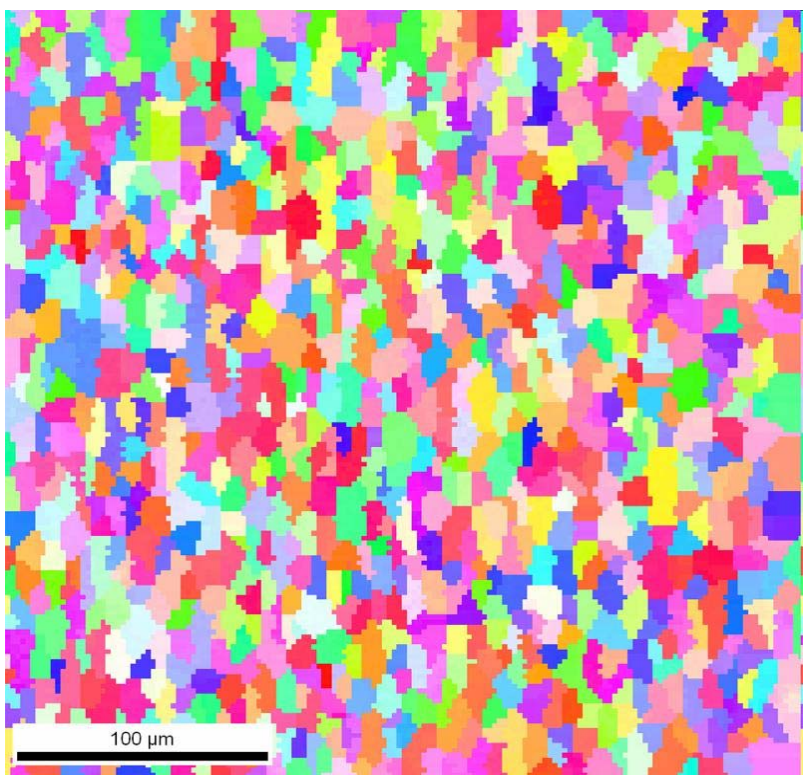

Figure 1. Microstructure of the starting material 3.

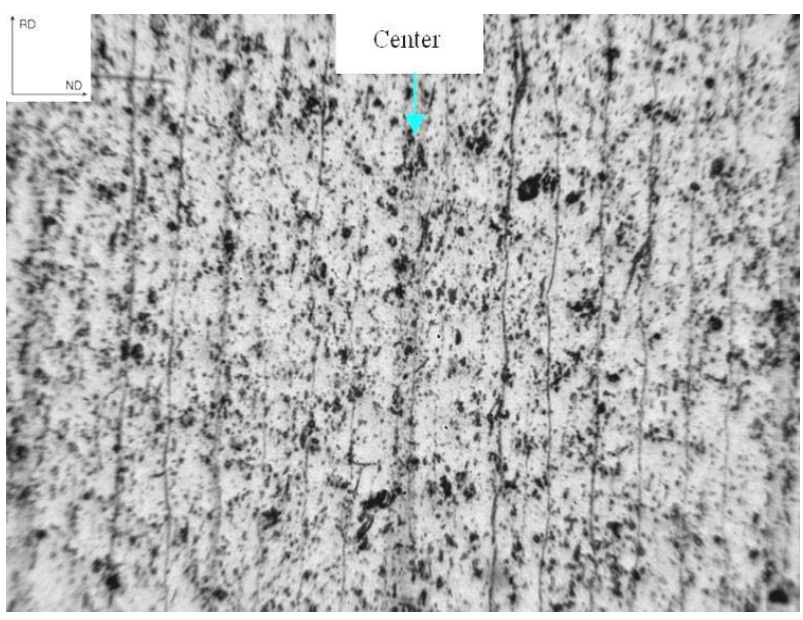

Figure 2. Optical micrograph of the longitudinal cross-section of AA5083 sheet after 6 ARB cycles. 
size of $200 \mathrm{~nm}-400 \mathrm{~nm}$ in which the density of dislocations is extremely low. Because of small grain sizes of severe plastic deformed materials, many previous investigations have relied on the TEM to study the grain structures after processing. The selected area diffraction (SAD) pattern consists of rings of diffraction spots suggesting that the most grain boundaries are separated by boundaries with high angles of misorientation. It must be considered that many of the grain sizes quoted from TEM analysis are underestimates as they include sub-grains [6].

Figure 4 shows the stress-strain curves and the corresponding tensile properties of the ARBed processed AA5083 sheets. Ultimate tensile strength increases up to $325 \mathrm{MPa}$ after two cycles, which is more than 1.25 times as high in comparison to the starting material. The tensile and the yield strengths (according to elongation of $0.2 \%$ ) increase during the following cycles, but with very smaller increments for the last cycles. The yield strength reaches $265 \mathrm{MPa}$ after 6 cycles, which is almost 1.7 times as high as the annealed material. The shapes of the stress-strain curves are similar in all samples and the ARBed specimens reach their peak of strength followed by a small value of necking strain. After 6 ARB cycles, the elongation decreases to $11.4 \%$, which means that the material still shows a sufficient ductility. The combination of elongation, yield and ultimate tensile strength points out that this material has desirable toughness for special applications.

The variation of hardness shown in Figure 5 confirms the results of the tensile tests. Rapid increase in the hardness and the strength at the strain of up to 1.6 is mainly due to the work hardening caused by an increase in dislocation density and formation of sub-grains [10].

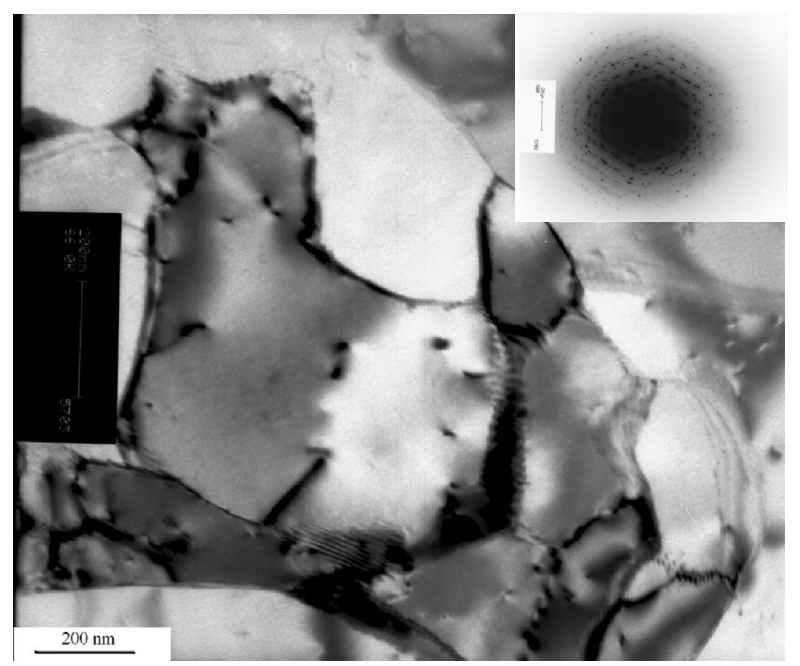

Figure 3. TEM micrograph of the sample processed by $6 \mathrm{cy}$ cles of ARB process.

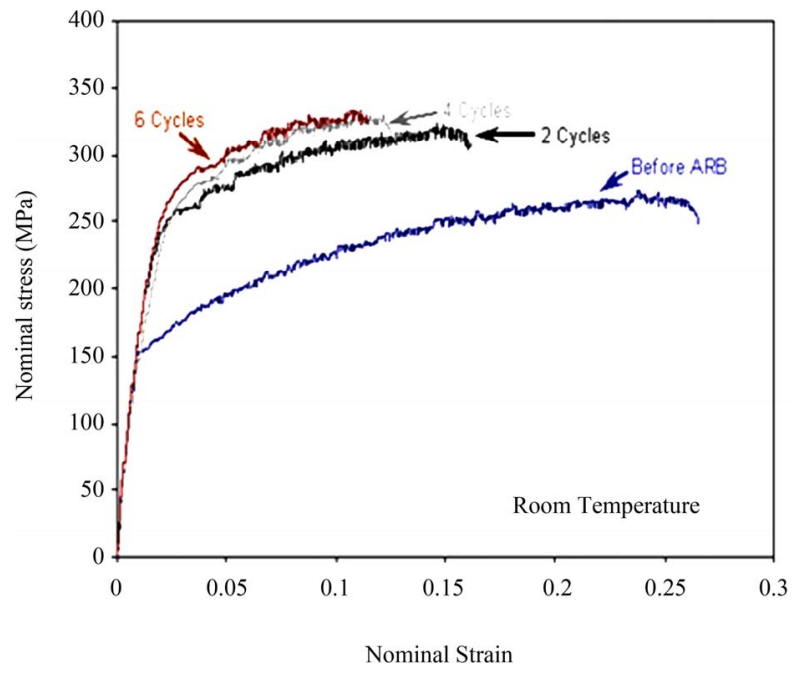

Figure 4. Nominal stress-strain curves of the AA5083 sheets processed at different ARB cycles.

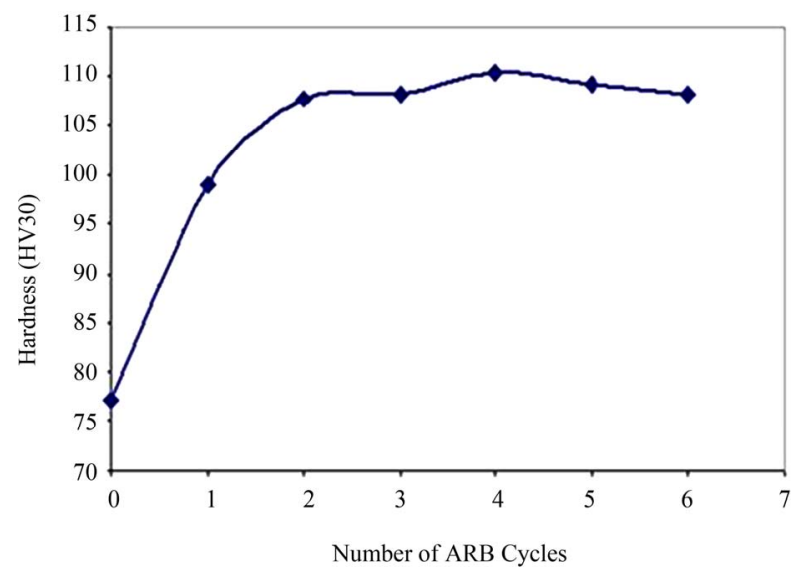

Figure 5. Macrohardness variation of AA5083 with increasing the number of ARB process.

During the following cycles, the dislocation density is almost constant. The occurrence of static and dynamic recoveries (as two flow softening mechanisms during the hot rolling and reheating at the temperature of $300^{\circ} \mathrm{C}$ ) causes that the generation and annihilation of dislocations reach an equilibrium state [10]. The increase in strength after cycle 2 can be attributed to the decrease of grain size and an increase in the volume fraction of HAGBs and misorientation. As a result, the strength of the ARBed samples can be considered as the sum of dislocation strengthening from LAGBs and grain size strengthening from HAGBs.

By using the below empirical relationship, the cell size which is the same value of the (sub) grain size can be estimated [11]:

$$
\delta=\frac{K G b}{\left(\tau-\tau_{0}\right)}
$$


Table 2. The values used for the present estimation and the cell size predicted from Equations 1and 2.

\begin{tabular}{ccccc}
\hline $\mathrm{G}(\mathrm{GPa})$ & $(\mathrm{MPa}) \boldsymbol{\sigma}$ & $(\mathrm{MPa}) \boldsymbol{\tau}$ & $\mathrm{K}$ & $(\mathrm{nm}) \boldsymbol{\delta}$ \\
\hline 27 & 260 & 104 & 5 & 360 \\
\hline \multicolumn{3}{c}{$K=0.9 \ln \left(\frac{G}{\tau}\right)$} &
\end{tabular}

Where $\delta$ is the cell size, $G$ is the shear modulus, $b$ is the burgers vector, $\tau$ is the resolved shear stress, and $\tau_{0}$ is the friction stress which is usually neglected since $\tau_{0} \ll \tau$. The value of $\tau$ is calculated by the following equation [11]:

$$
\tau=\frac{\sigma}{M}
$$

where $M$ and $\sigma$ are the Taylor factor ( the value of 2.5 is used for the present work) and the flow stress, respectively. The (sub) grain size is predicted from equation. 1 and 2. The values used for the present estimation are listed in Table 2. According to these values for the sample processed by 6 cycles of the hot ARB process; the predicted grain size is $360 \mathrm{~nm}$ which has a good agreement with the TEM result. Also, it is possible to approximate the dislocation density retaining in the grain interior. The flow stress is related to the dislocation density $(\rho)$ by the following equation [11]:

$$
\tau=\tau_{0}+\alpha G b \rho^{1 / 2}
$$

where $\tau_{0}$ is strain insensitive and can be neglected as described previously. The dislocation densities for the present work and Saito's study were estimated $0.72 \times$ $10^{15}$ and $3.23 \times 10^{15} \mathrm{~m}^{-2}$, respectively. These results show that a large part of the obtained yield stress for Saito's work can be attributed to the high density of dislocations.

\section{Conclusions}

In this study, a hot ARB process was performed on an AA5083 sheet up to 6 cycles and equivalent strain of 4.8 was successfully achieved without severe edge cracking. The results confirmed that the process is effective for the grain refinement of AA5083.

The mechanical properties revealed that the strength of the sheet considerably increased by the first two ARB cycles which is attributed to work hardening caused by an increase in dislocation density and sub-grains. After 6 cycles, (sub) grains with a low internal dislocation density have a size with the range of $200-400 \mathrm{~nm}$.

\section{References}

[1] P. B. Prangnell, J. R. Bowen and A. Gholinia, "The Formation of Submicron and Nanocrystalline Grain Structure by Severe Deformation," Proceedings of the 22nd Risø" International Symposium on Materials Science, Roskilde, 2001, pp. 105-126.

[2] Y. S. Kim, S. H. Kang and D. H. Shin, "Effect of Rolling Direction on the Microstructure and Mechanical Properties of Accumulative Roll-Bonding (ARB) Processed Commercially Pure 1050 Aluminum Alloy," Materials Science Forum, Vol. 503-504, 2006, pp. 681-686. doi:10.4028/www.scientific.net/MSF.503-504.681

[3] K. F. Zhang and H. H. Yan, "Deformation Behavior of Fine-Grained 5083 Al Alloy at Elevated Temperature," Transactions of Nonferrous Metals Society of China, Vol. 19, 2009, pp. 307-311. doi:10.1016/S1003-6326(10)60060-X

[4] J. Lee and H. Seok, "Microstructural Evolutions of the Al strip Prepared by Cold Rolling and Continuous Equal Channel Angular Pressing," Acta Materialia, Vol. 50, 2002, pp. 4005-4019. doi:10.1016/S1359-6454(02)00200-8

[5] R. K. Islamgaliev, N. F. Yunusova, R. Z. Valiev, N. K. Tsenev, V. N. Perevezentsev and T. G. Langdon, "Characteristics of Superplasticity in an Ultrafine-Grained Aluminum Alloy Processed by ECA Pressing," Scripta Materialia, Vol. 49, 2003, pp. 467-472. doi:10.1016/S1359-6462(03)00291-4

[6] Y. Saito, H. Utsunomiya, N. Tsuji and T. Sakai, "Novel Ultra-High Straining Process for Bulk Materials Development of the Accumulative Roll-Bonding (ARB) Process," Acta Materialia, Vol. 47, 1999, pp. 579-583. doi:10.1016/S1359-6454(98)00365-6

[7] N. Tsuji, Y. Saito, S. H. Lee and Y. Minamino, "ARB (Accumulative Roll-Bonding) and Other New Techniques to Produce Bulk Ultrafine Grained Materials," Advanced Engineering Materials, Vol. 5, 2003, pp. 338-344. doi:10.1002/adem.200310077

[8] X. Huang, N. Tsuji, N. Hansen and Y. Minamino, "Mi Crostructural Evolution During Accumulative Roll-Bonding of Commercial Purity Aluminum," Materials Science and Engineering: A, Vol. 340, 2003, pp. 265-271. doi:10.1016/S0921-5093(02)00182-X

[9] K. T. Park, J. H. Park, Y. S. Lee and W. J. Nam, "Comparison of Compressive Deformation of Ultrafine-Grained 5083 Al Alloy at 77 and $298 \mathrm{~K}$," Metallurgical and Materials Transactions: A, Vol. 36, 2005, pp. 1365-1368. doi: 10.1007/s11661-005-0227-8

[10] K. T. Park, H. J. Kwon and W. J. Kim, "Microstructural Characteristics and Thermal Stability of Ultrafine Grained 6061 Al Alloy Fabricated by Accumulative Roll Bonding Process," Materials Science and Engineering: A, Vol. 316, 2001, pp. 145-152. doi:10.1016/S0921-5093(01)01261-8

[11] K. T. Park, J. H. Park, Y. S. Lee and W. J. Nam, "Microstructures Developed by Compressive Deformation of Coarse Grained and Ultrafine Grained 5083 Al Alloys at $77 \mathrm{~K}$ and $298 \mathrm{~K}$," Materials Science and Engineering: A, Vol. 408, 2005, pp. 102-109. doi:10.1016/j.msea.2005.07.040 